\title{
GROUP FORMATION IN A PUBLIC GOOD EXPERIMENT \\ on the dynamics of social ties structures
}

\author{
Joep Sonnemans ${ }^{\mathrm{a}}$, Frans van Dijk ${ }^{\mathrm{b}}$ and Frans van Winden ${ }^{\mathrm{a}}$
}

\begin{abstract}
Economic behavior often takes place in groups of small numbers of people interacting with each other (like work teams, neighborhoods, social networks, etc.). Characteristic of such interaction is the development of (affective) interpersonal relationships, or social ties. According to sociologists, the embeddedness of economic behavior in networks of social ties has a profound impact on economic performance. Although, in economics, there is a growing awareness of the significance of social factors, the study of social dynamics is still in its infancy. In this paper we investigate experimentally the development of social ties structures, and thereby the formation of informal groups, through economic interaction in a public good environment. It turns out that complicated dynamics arise from individual differences in social value orientation and (affective) response patterns. Our findings point at the importance of leadership in controlling and channeling emotions and sentiments to build effective groups, like teams or communities. This leads to a different perspective on management than the one provided by standard agency theory.
\end{abstract}

November 1999

${ }^{a}$ CREED, Department of Economics, University of Amsterdam, Roetersstraat 11, 1018 WB Amsterdam, The Netherlands. E-mail: joeps@fee.uva.nl, fvwinden@fee.uva.nl.

${ }^{\mathrm{b}}$ Ministry of Justice, The Hague.

"This paper is part of the EU-TMR Research Network ENDEAR (FMRX-CT98-0238). At the time of the experiment Frans van Dijk was affiliated with CREED. Financial support from the Netherlands' Organization for Scientific Research (NWO) is gratefully acknowledged. We also thank Otto Perdeck for the development of the software used in the experiment. 


\section{Introduction}

Economic behavior, in the private as well as the public sector, often takes place in groups of small numbers of people interacting with each other. Think of work teams, committees, boards of directors, governmental bureaus, households, or neighborhoods. At closer inspection, this even happens in situations modeled by standard economic theory as involving the anonymous interaction of many agents. Examples are competitive commodity markets and corporate shareholding. In many commodity markets small networks of entrepreneurs, subcontractors and customers exist (Granovetter 1985, Uzzi 1996). And, in case of public companies, shares are often heavily concentrated in the hands of a small number of major shareholders (La Porta et al. 1998). ${ }^{1}$ In all these settings people often have little or no choice with whom to interact, since the cost of leaving the group may be very high. This directs attention to an issue which is largely ignored in economics, which is social dynamics. While in the theoretical many-agents abstraction the dynamics of social relationships may be safely neglected, this is not so in the real world of small number interaction. In that case, social factors like loyalty, social approval or status, which have recently attracted some attention in the economics literature (see Akerlof 1983, Holländer 1990, Bernheim 1994), become relevant. However, this also holds for such easily recognized, though hardly studied, affective influences like personal chemistry, emotions, antagonisms or affinities. The following statement by Boonstra, CEO of Philips, illustrates: "A company is a concentration of human emotions (...) Sometimes you want to achieve something, and you observe that it will not happen. Then, waves of emotions pay a role, and bridges cannot be built. Most conflicts in organizations occur because emotions are not controlled". ${ }^{2}$ Contemporary sociologists have forcefully argued that the embeddedness of economic behavior in networks of affective interpersonal relationships (social ties) has a profound impact on the economic performance of markets and organizations (see, e.g., Coleman 1984, Turner 1999). In economics, the importance of social ties for economic behavior was already noticed by Adam Smith (1984 [1759], part IV, section II): "Colleagues in office, partners in trade, call one another brothers; and frequently feel towards one another as if they really were so. Their good agreement is an advantage to all." In a similar vein Alfred Marshall (1961 [1890]) related labor market rigidity to the reluctance of workers to migrate due to old associations. More recently, economists have particularly paid attention to the impact of affective relations within the family (e.g., Becker 1981). Interpersonal relations outside families have only occasionally received attention. ${ }^{3}$

\footnotetext{
${ }^{1}$ According to La Porta et al., worldwide the average ownership of the three largest shareholders in publicly traded companies is 46 percent. They conclude that dispersed ownership of public companies is a myth.

${ }^{2}$ Interview in the Dutch newspaper Volkskrant, 24-12-1998 (translated from Dutch).

${ }^{3}$ For instance, in the context of job search (Boorman 1973), price formation (Okun 1981), the functioning of organizations (Rotemberg 1994), and the private provision of public goods (van Dijk and van Winden 1997). See also Dasgupta (1999) who surveys issues and literature related to the notion of social capital.
} 
For these reasons, we think it is appropriate and productive to pay more attention to social dynamics in economics. This paper is intended to contribute to the development of this line of research. Specifically, our goal is to investigate experimentally the development of (affective) social ties structures - and thereby the formation of informal groups - through economic interaction in a public good environment. By focusing on the dynamics of social ties, instead of the consequences of the assumed existence thereof, and group formation, this paper addresses in our view an important lacuna in the existing literature. The use of laboratory experimentation as research method is helpful in this respect, since a solid empirical study of the dynamics of interpersonal relations is difficult to achieve in the field, due to observational and control problems. Our focus on how groups develop in a public good environment, moreover, seems relevant for various (political) economic contexts. One can think of crime prevention, environmental protection, voter turnout (political participation), and the performance of organizations. For instance, organizational studies have well established that the social structure of an organization clearly affects the willingness of its members to cooperate, coordinate, share information, and to trust and support other members, which obviously influences its performance (e.g., Scott 1981, Forsyth 1990). Finally, this study may also contribute to the recent debate on extrinsic versus intrinsic motivation (e.g., Frey 1997, Kreps 1997), since social ties provide a mechanism through which intrinsic motives enter as a determinant of behavior, along with the extrinsic incentives provided by the environment itself.

To make this last point clearer we need to be more specific about the notion of a social tie. Following a recent survey on interpersonal attachments (Baumeister and Leary 1995), the affective component - sentiments - can be considered as the key element. Sentiments that individuals have with respect to specific others are closely related to the extent they care about the well-being of those others, which suggests a formalization in terms of utility interdependence (Coleman 1984). However, it is important to note that a social tie is not simply determined by the weight that an individual attaches to the well-being or utility of another subject. ${ }^{4}$ This would only be the case if individuals are neutral towards people they do not know. If positive or negative sentiments are maintained towards others in general, a social tie with a specific individual can only be said to exist if the weight attached to this specific other's well-being differs from the weight given to the well-being of others in general (a generalized other). ${ }^{5}$ Therefore, to establish the existence of a social tie, two interpersonal

\footnotetext{
${ }^{4}$ In the sociological literature a social tie is usually seen as a mutual, two-sided relationship. A tie between between individuals $i$ and $j$ would then consist of $i$ 's sentiments about $j$ and $j$ 's sentiments about $i$. However, for ease of exposition and because sentiments are often not symmetric (see Wellman 1988), we will speak of $i$ 's social tie with $j$ without immediate reference to $j$ 's sentiments about $i$, and vice versa.

${ }^{5}$ Of interest in this respect are the results of public good experiments. Among experimentalists there is a growing consensus that different types of individuals exist (see Ledyard 1995). There are some who (almost) never contribute to the public good, when it is a dominant strategy for rational selfish individuals not to do so, whereas others (almost) always contribute. This may well be related to differences in attitudes towards others in general.
} 
orientations need to be measured: the orientation of an individual towards the interests of an unknown, generalized other, and the orientation towards the interests of a specific individual. In the experiment this will be done with the help of a new measuring device, called the 'circle-test' (see section 2). The next question is how social ties - providing an intrinsic motivation to advance (if positive) or harm (if negative) the interests of the specific others involved - develop. It is generally acknowledged that ties develop through prolonged interaction, and erode when the interaction ends (Feld 1981, Granovetter 1985, Coleman 1990, Levine and Moreland 1998). These authors further suggest that ties are largely the unconscious by-product of social interaction (see also Granovetter 1992). Field studies seem to confirm this (e.g., Aldrich 1995). Dependent on whether the interaction is valued positively or negatively, positive or negative sentiments are formed (Homans 1950, 1961, Feld 1981, Fararo 1989). It may be expected therefore that (rudimentary) social ties will develop during a repeated public good game, as studied in this paper, and that these ties will depend on the payoff of the interaction.

The organization of this paper is as follows. Section 2 goes into the design and procedures of the experiment. Results are presented in section 3, while section 4 concludes. 


\section{Design and procedures of the experiment}

In 4 sessions a total number of 56 subjects participated, of which 35 were students of economics. On average 51 Dutch guilders (approximately US\$25) were earned by the subjects in about 1.5 hours. The experiment was completely computerized, and took place in the CREED-laboratory of the University of Amsterdam. Table 1 gives an overview of the sequence of events. In short, each session started with an application of the 'circle-test' (see below), followed by 32 periods of a repeated 4-person public good game. After 25 periods this game was - without prior announcement - interrupted for a second application of the circle-test, after which the game continued for the remaining seven rounds. Details concerning the circle-tests, the public good game, and the experimental procedures are discussed next.

\section{Circle-test}

To measure social ties we will use an instrument inspired by the so-called 'ring-test of social value orientation' (Liebrand 1984). The ring-test asks subjects to make a series of 24 choices between ownother payoff combinations. Each own-other payoff combination allocates a positive or negative amount of money to the decision maker her/himself and to the subject with whom the individual is anonymously matched. The pairs of allocations lie on a circle with the origin as center (which explains the name of the test). The horizontal axis measures the amount of money allocated to the person her- or himself (S), and the vertical axis the amount of money allocated to the other $(\mathrm{O})$. Each allocation can be considered as a vector. If for each subject the preferred allocations are added, the angle of the resulting vector with the horizontal axis is a measure of the extent the individual cares about the other. The ring-test has proven to be an useful tool for measuring attitudes towards an unknown, generalized other (called social value orientation by psychologists). The predictive validity of the test, inside as well as outside the laboratory, has been shown by many studies (see, e.g., Rusbult and van Lange 1996). For an application in an economic experiment see Offerman, Sonnemans and Schram (1996).

For measuring attitudes towards several specific others the ringtest in its original form is not practical. Repeated measurements would result in too many questions and would cost too much time. We therefore developed the circle-test. In the circle-test the attitude of a subject towards someone else is measured by only one decision. Subjects are requested to select a point on a circle that is presented to them on the computer screen, where each point on the circle represents an allocation of money to the person her/himself (S) and another person $(\mathrm{O})$. The amounts allocated can be positive or negative, with $\mathrm{S} 2+\mathrm{O} 2=(1000) 2$, and are expressed in points (where 200 points are equal to 1 Dutch guilder, approximately 0.5 US dollar). Figure 1 shows the computer screen of the circle-test. Subjects receive computerized instructions. They have to practice using the mouse or keyboard to select an allocation of money, and they have to answer some questions correctly before proceeding (to check understanding). The circle-test starts with the computer program displaying a circle without an arrow. When the subject clicks somewhere on the circle, an arrow is displayed and in the right upper part of 
the screen the amounts for Self and Other are shown. The subject can move the arrow by clicking on the circle or using the keyboard. Every time the amounts in the right upper part of the screen are updated. The final decision has to be confirmed.

Table 1. Sequence of events.

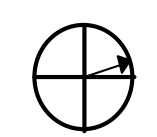

Circle-test. Subjects allocate a positive or negative amount of money to themselves (S, horizontal axis) and an anonymous other $(\mathrm{O}$, vertical axis). Payoffs are disclosed after the experiment.

Four-person public good game.

Subjects observe each period the decisions of the other group members:

$\mathrm{A}, \mathrm{B}$ and $\mathrm{C}$.

32 periods are announced, after 25 periods the game is interrupted.

WWWWW

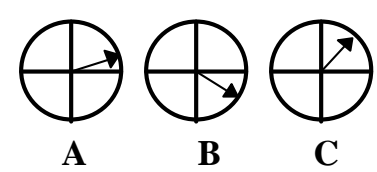

Circle-tests. Subjects allocate positive or negative amounts of money to themselves and to their group members A, B and C. Payoffs are disclosed after the experiment.

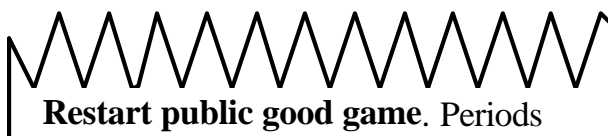
26-32 are played.

Subjects fill in a short questionnaire.

Results of the circle-tests are revealed.

Subjects are paid privately. 


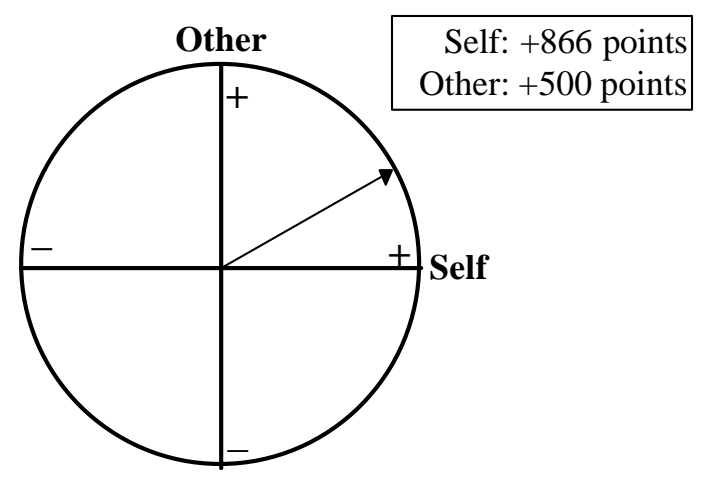

Figure 1. The computer screen of the circle-test. The position of the arrow can be changed by clicking with the mouse on the circle or using the keyboard. The numbers (points) shown are automatically updated. In the three circle-tests after the 25 periods of the public good game, a scrollable table with results of the public good game is displayed in the lower part of the screen.

The experiment starts with a circle-test to measure the attitude towards an anonymous (generalized) Other. The public good game played subsequently is (unexpectedly) interrupted after the 25 th period and three more circle-tests are carried out. In each of these tests the Other is one of the group members in the public good game, labeled A, B or C. During the tests the subjects can still see the results of the public good game: the decisions of the $\mathrm{A}, \mathrm{B}$ and $\mathrm{C}$ member, and their own decisions in the game. In this way, the circle-tests can measure whether the attitude of a subject towards a group member is influenced by the behavior of this group member in the public good game. For example, one would expect a more positive (less negative) angle towards a member who contributed more in the game.

\section{Public good experiment}

Subjects were randomly assigned to a four-person group. The composition of the groups stayed constant for all 32 periods. The other three group members were identified as A, B and C. In each period a subject had to distribute an endowment of 10 markers over two activities $X$ and $Y$. Activity $X$ generated earnings exclusively for the subject her/himself (private account), whereas activity $Y$ generated earnings for all group members (public account). For each subject the endowment of markers was the same in all periods. Every marker in the public account earned 7 points for all group members, while the value of $i$ markers in the private account was: $21 * i-i^{2}$. Fixed costs of 60 points were subtracted each period.

The first period started after everybody had finished the computerized instructions. Each period subjects had to type in how many markers they wanted to spend on activities $X$ and $Y$. After each period they received feedback about the number of markers spent by each other group member (A, B, and C) on activity $Y$ and their own earnings. In the lower part of the screen the decisions and results of previous periods were displayed. Subjects could access information about all previous periods by using the pageup and page-down keys. 
Under the usual (benchmark) assumption of rational own-payoff maximization, the subgameperfect Nash equilibrium of the game is characterized by dominant strategies. The dominant strategy is to put in each period game 3 markers in the public account and 7 markers in the private account. The Pareto-optimal outcome, on the other hand, entails that subjects put all markers into the public account. Players earn 122 points in the Nash equilibrium and 220 points in the Pareto-optimal outcome, where each point is equal to 0.5 Dutch cents.

\section{Procedures}

Subjects were recruited by announcements on bulletin boards in university buildings and an advertisement in the university newspaper. After all subjects were seated, computerized instructions for the first part (the circle-test) were started. The instructions contained some questions to check understanding. After the instructions all subjects took the decision required by the test. Subjects did not receive any feedback about the results of this test (nor about the results of the later circle-tests) until the whole experiment was finished. Information about the public good game was only given after the end of the first circle-test. A translation of the instructions is provided in the Appendix.

The payoff structure of the public good game was explained with a table on the computer screen and on a handout, and subjects had to calculate some outcomes to check understanding. The table was also projected on the wall to show subjects that everybody had the same table. The number of periods (32) was also public knowledge. Subjects did not know, however, that the public good experiment would be interrupted after period 25 .

After 25 periods the public good experiment was interrupted and the instructions for the second circle-test were started (see Apendix). In this case, subjects had to perform the test three times, where the Other in these tests concerned the subjects A, B and C, respectively (their fellow group members in the public good experiment). The results of all 25 periods of the public good experiment remained accessible to them on the lower part of the screen. Subjects could scroll to see their own decisions as well as the decisions of the $\mathrm{A}, \mathrm{B}$ and $\mathrm{C}$ subject.

The public good experiment was restarted after everybody had finished the three circle-tests, and periods 26-32 were played. After the experiment, subjects filled in a short questionnaire and were subsequently paid, one at a time, in another room. 


\section{Results}

In this section we first present some general results concerning the measurement of social ties (the circletests) and the public good experiment. This is followed by a discussion of the formation and impact of social ties. Finally, we go into the typology of the observed social ties and the issue of group formation.

\subsection{Measurement of social ties and contributions to the public good}

\section{Measurement of social ties}

The outcomes of the first ('pre') circle-test and the three second ('post') circle-tests can be summarized as follows. The mean of the angles in the post-tests $\left(11.2^{\circ}\right)$ differs hardly from the mean angle in the pretest $\left(13.4^{\circ}\right)$. A small negative drift of $-2^{\circ}$ is observed. This disguises, however, the changes that took place at the individual level. The mean of the absolute differences between the pre- and post-tests is $13^{\circ}$. This goes together with an increase of the standard deviations (from 15.7 to 19.3). Of the 55 subjects $^{6}, 14$ chose an angle of approximately $0^{\circ}\left(-5^{\circ} \leq\right.$ angle $\left.\leq 5^{\circ}\right)$ in both the pre- and the post-tests, while 13 chose approximately $0^{\circ}$ in the pre-test and a positive or negative angle in at least one of the post-tests. Only 3 subjects chose $0^{\circ}$ in the post-tests only. Thus, the number of subjects that consistently or only later on displayed purely selfish behavior is relatively small. Not surprisingly, $98 \%$ of the angles fell within the interval $\left[-45^{\circ}, 45^{\circ}\right]$, which implies that the absolute weight attached to the Other's payoff is almost never larger than 1 . The increase in the standard deviation of the pre- and post-tests angles could be caused by subjects differentiating between their group members. It may also be caused by groups going through different experiences. We will see that both factors play a role.

Table 2. Positive, neutral and negative attitudes of subjects towards others.

\begin{tabular}{|l|c|c|c|c|}
\hline & positive & neutral & negative & total \\
\hline social value orientation (pre-test) & $26(47 \%)$ & $28(51 \%)$ & $1(2 \%)$ & 55 \\
\hline sentiments towards specific subjects (post-tests) & $80(48 \%)$ & $73(44 \%)$ & $12(8 \%)$ & 165 \\
\hline social ties (difference of post- and pre-tests) & $41(25 \%)$ & $76(46 \%)$ & $48(29 \%)$ & 165 \\
\hline
\end{tabular}

Note: neutral attitudes are defined as attitudes between $-5^{\circ}$ and $+5^{\circ}$.

Results can also be expressed in percentages of positive, neutral or negatives attitudes. Table 2 illustrates. Negative social value orientations (pre-test angles) hardly occur. Negative sentiments towards

\footnotetext{
${ }^{6}$ Of the 56 subjects, one person did not understand the instructions of the test. The subject expressed this confusion in the debriefing questionnaire. This led to erratic choices, as the subject changed her or his interpretation of the test during the post-tests. The data for this person are deleted.
} 
specific subjects (post-tests angles) occur more often, while negative social ties occur as much as positive ties. In $46 \%$ of the cases no ties were formed. It is noted that the subjects who choose an angle of $0^{\circ}$ in the pre-test and all post-tests already cause $27 \%$ of all social ties to be neutral.

To check the validity of the social ties measurement, we included in the debriefing questionnaire the sociometric question whether they would want to continue with their current partners (asked for A, B and C, separately) or preferred to be matched with another subject, in case the public good experiment were repeated. One would expect that the more positive the tie with a person the stronger the inclination to continue with this person. The results are supportive. The correlation coefficients concerning the willingness to continue, on the one hand, and sentiments and social ties, on the other hand, are .46 and .36 , respectively. Both are significant at the .001 level.

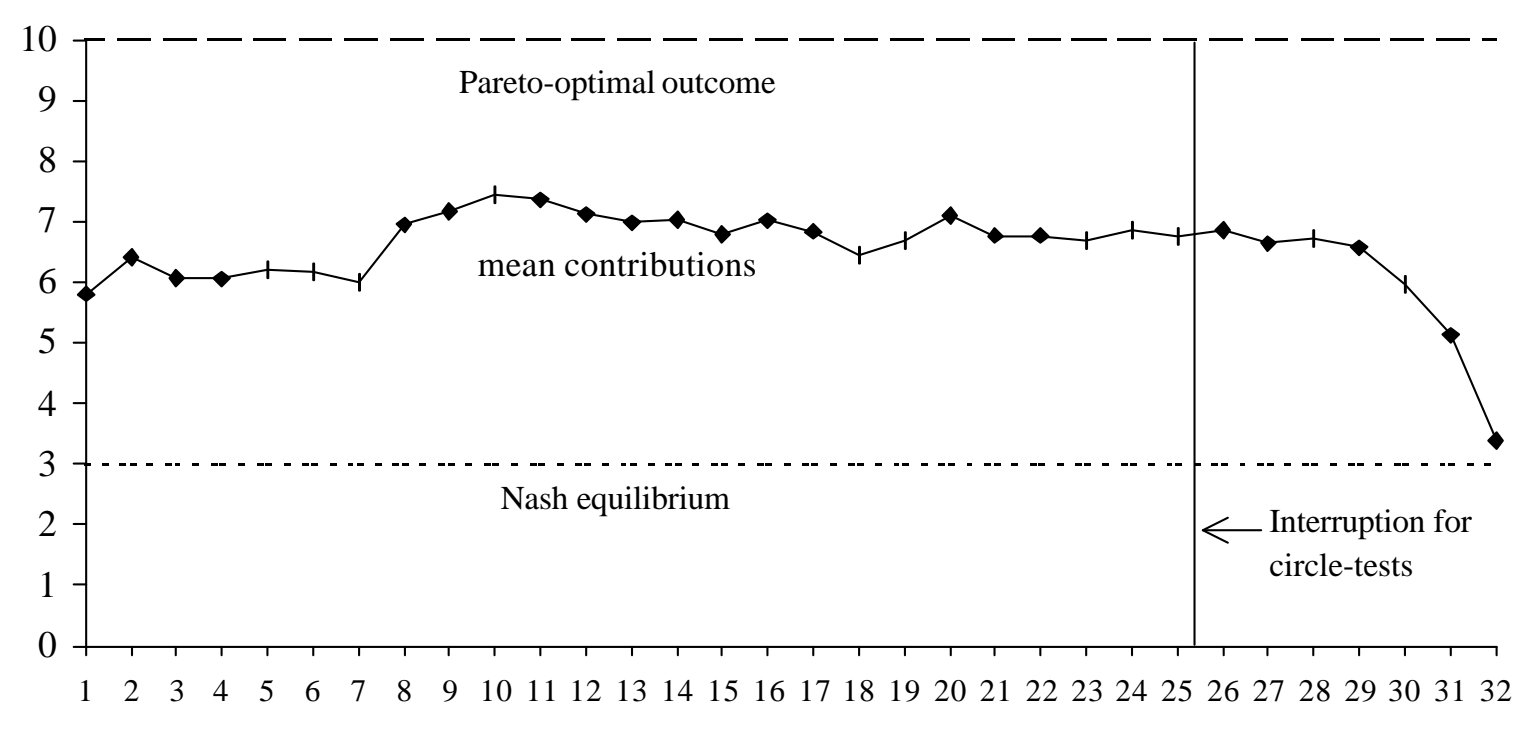

Period

Figure 2. Average individual contributions to the public good per period.

\section{Public good game}

Figure 2 shows the mean contributions to the public good by period. On average, subjects contribute persistently and substantially more than the Nash equilibrium for own-payoff maximizers would imply, except for the last period. Towards the end the for this type of game usual decline occurs (see, e.g., Ledyard 1995). The interruption after period 25 shows no effect on contributions: the contributions in period 25 do not differ significantly from those in period 26 (two-tailed Wilcoxon test, at the group level: $\mathrm{p}=.7598)$.

Between groups large differences exist. In the next subsection we will investigate to what extent social value orientations and social ties can shed a light on the observed development of contributions. 


\subsection{Formation and impact of social ties}

\section{Formation of social ties}

Our hypothesis is that social ties arise as a result of the interaction in the public good game. First, we address the question whether subjects who contributed more to the public good are more appreciated by their group members than subjects who contributed less. For each subject we calculate the average sentiment of the three partners towards this subject (the average angle of the post-tests). This sentiment correlates highly with the contributions of the subject in the public good game: $\mathrm{R}=0.51$ if period 1 to 25 are considered, and 0.42 if only periods 1 to 5 are taken into account. The average social tie towards a subject also correlates highly with the contributions of that subject; $R=0.49$ if periods 1 to 25 are considered, and $\mathrm{R}=0.56$ for periods 1 to 5 . All these correlations are statistically highly significant $(\mathrm{p}<0.01)$.

Of course, one would expect that the attitude of a subject towards a specific other does not only depend on the characteristics of this specific other (that is, her or his contributions in the public good game) but also on the social value orientation of the subject. This is indeed what we find. Table 3 shows a linear regression with the post-test angle as dependent variable and the social value orientation of the subject and the contributions of the specific other as independent variables. Both variables appear to have a large impact. The results are roughly the same if only the contributions in periods 1 to 5 are considered (not in table).

Table 3: Linear regression with the angle measured by the post-test as a dependent variable and, as independent variables, the angle measured by the pre-test and the contributions of the other subject in periods $1-25$.

$\begin{array}{lrrrrr} & \text { B } & \text { SE B } & \text { Beta } & \mathrm{t} & \text { Sign. t } \\ \text { Social Value Orientation } & .366 & .086 & .298 & 4.279 & .0000 \\ \text { Contributions of the other in periods 1-25 } & .126 & .025 & .355 & 5.099 & .0000 \\ \text { Constant } & -15.118 & 4.536 & & -3.333 & .0011\end{array}$

Multiple R: 0.465

Adjusted R Square: 0.207

A priori one cannot exclude the possibility that subjects develop a general attitude towards their group, reflecting how well the group did in the public good game, and base their decisions in the post-tests only upon this. Alternatively, subjects may actively discriminate between their group members and have a more positive attitude towards those group members who contributed more in the public good game. The correlation results reported above, however, suggest that the latter motivation is at work. To test this more directly we will now look at intra-person comparisons. As discussed in section 2, we developed the circle-test specifically for this purpose. As a test we compute across all subjects the correlation between, on the one hand, the difference in the post-test angles regarding alternative pairs of group members and, on the other hand, the difference in the contributions of these group members. It turns out that the 
correlation is 0.57 if all 25 periods before the post-tests are taken, and 0.55 if only periods 1 to 5 are considered (both significant at the .001 level). These correlations show that during the public good game the subjects have built specific bonds with specific group members, rather than a general 'group cohesion'. We will come back to this in section 3.3.

\section{Impact of social ties}

An interesting question is whether the attitudes of the subjects towards each other influence their behavior in the public good game. First we test whether the social value orientation, as measured in the pre-test, affects behavior in the first periods of the public good game. This does not appear to be the case, since no correlation is found between the pre-test angles and the contributions in the first period or the first five periods. Many of the subjects with a pre-test angle of $0^{\circ}$ nevertheless contribute (substantially) more than the 'Nash equilibrium' strategy would imply in that case ( 3 per period). A possible explanation is the presence of some form of 'conditional cooperation' (Keser and van Winden 1999; see also Sonnemans, Schram and Offerman 1999).

To examine whether the post-test angles are consistent with behavior in the public good game after its resumption in period 26, we average the three angles of the post-tests per subject and correlate the resulting measure with the subject's contributions in the periods 26-32. The mean post-angle per subject correlates highly $(\mathrm{R}=0.59, \mathrm{p}<0.001)$ with the sum of the contributions in period 26 to 32 . As is to be expected, the correlation with behavior (contributions) in the first 25 periods is much weaker $(\mathrm{R}=0.29)$.

\subsection{Typology of social ties and group formation}

So far, we have focussed on one-sided sentiments and one-sided social ties, neglecting whether these are also mutual. In this section mutual sentiments and ties are examined. Furthermore, we will look at group structure, that is, the formation of (informal) groups through social ties. A first question that arises is whether a tendency exist towards symmetric mutual sentiments and ties. Table 4 shows the results. 
Table 4. Mutual sentiments and social ties.

\begin{tabular}{|l|c|c|c|}
\hline & & $\begin{array}{c}\text { sentiments towards } \\
\text { specific subjects }\end{array}$ & social ties \\
\hline type & sign & percentage of pairs & percentage of pairs \\
\hline symmetric & ++ & 29 & 10 \\
\hline & -- & 0 & 5 \\
asymmetric & +0 & 37 & 22 \\
\hline $\begin{array}{l}\text { mutually } \\
\text { neutral }\end{array}$ & 00 & 4 & 10 \\
\hline sum & $0-$ & 22 & 34 \\
\hline
\end{tabular}

Note: neutral attitudes $(0)$ are defined by angles between $-5^{\circ}$ and $+5^{\circ}$.

Sentiments are neutral and ties are absent in approximately $20 \%$ of the cases. Mutually positive sentiments occur in approximately $29 \%$ of all pairs. As mutually negative sentiments are absent, symmetry of (non-neutral) sentiments also occurs in $29 \%$ of the cases. Social ties show a different outcome. Mutually positive ties occur only in $10 \%$ of the cases, and (non-neutral) symmetric ties in general occur in $15 \%$ of the cases. Asymmetry is much more common (66\%). It is concluded that, in our public good environment, interaction among individuals with equal endowments and payoff structures does not lead to pervasive positive ties among them. Apparently, individual differences in social value orientation and reaction patterns that cannot be controlled for, result in complex dynamics. The suggestion borne out by the 'minimal group paradigm' literature and social identity theory (see Tajfel and Turner 1986, Taylor and Moghaddam 1994) that bonds form easily and lead to behavior favoring formal group members, needs to be qualified. Our results indicate that once interaction is allowed group cohesion can no longer be taken for granted.

On the basis of our experimental results, social ties structures (social networks) are likely to differ widely among groups, depending on the success of the interaction. To examine this, we compare the two worst performing groups in terms of mean contributions to the public good with the two best performing groups. Table 5 presents a comparison of the different types of ties in these groups. Whereas most of the ties in the best performing groups are (mutually) positive, most of the ties in the worst performing groups are either negative or neutral. Figure 6 shows the social ties structures in these groups. The networks of the two worst groups are quite similar, as are the networks of the successful groups. Among them the two types of networks differ considerably. Note, however, that also in the groups with successful interaction (groups 2 and 12), networks are far from complete and asymmetry of ties occurs. 
Table 5. Comparison of social ties in the two worst and the two best performing groups.

\begin{tabular}{|c|c|c|c|c|c|c|c|c|}
\hline & \multicolumn{4}{|c|}{ two worst groups } & \multicolumn{4}{|c|}{ two best groups } \\
\hline & \multicolumn{2}{|c|}{ group 5} & \multicolumn{2}{|c|}{ group 7} & \multicolumn{2}{|c|}{ group 2} & \multicolumn{2}{|c|}{ group 12} \\
\hline \multirow{2}{*}{$\begin{array}{l}\text { mean contr. } \\
\text { per period }\end{array}$} & \multicolumn{2}{|c|}{3.76} & \multicolumn{2}{|c|}{4.40} & \multicolumn{2}{|c|}{9.94} & \multicolumn{2}{|c|}{9.80} \\
\hline & sent. & ties & sent. & ties & sent. & ties & sent. & ties \\
\hline sign & cases & cases & cases & cases & cases & cases & cases & cases \\
\hline $\begin{array}{l}++ \\
--\end{array}$ & & & & & 2 & 2 & 2 & 1 \\
\hline $\begin{array}{l}+0 \\
+- \\
0-\end{array}$ & 3 & 2 & 1 & $\begin{array}{l}1 \\
3\end{array}$ & 3 & 3 & 4 & $\begin{array}{l}3 \\
1\end{array}$ \\
\hline 00 & 3 & 4 & 5 & 2 & 1 & 1 & & 1 \\
\hline sum & 6 & 6 & 6 & 6 & 6 & 6 & 6 & 6 \\
\hline
\end{tabular}
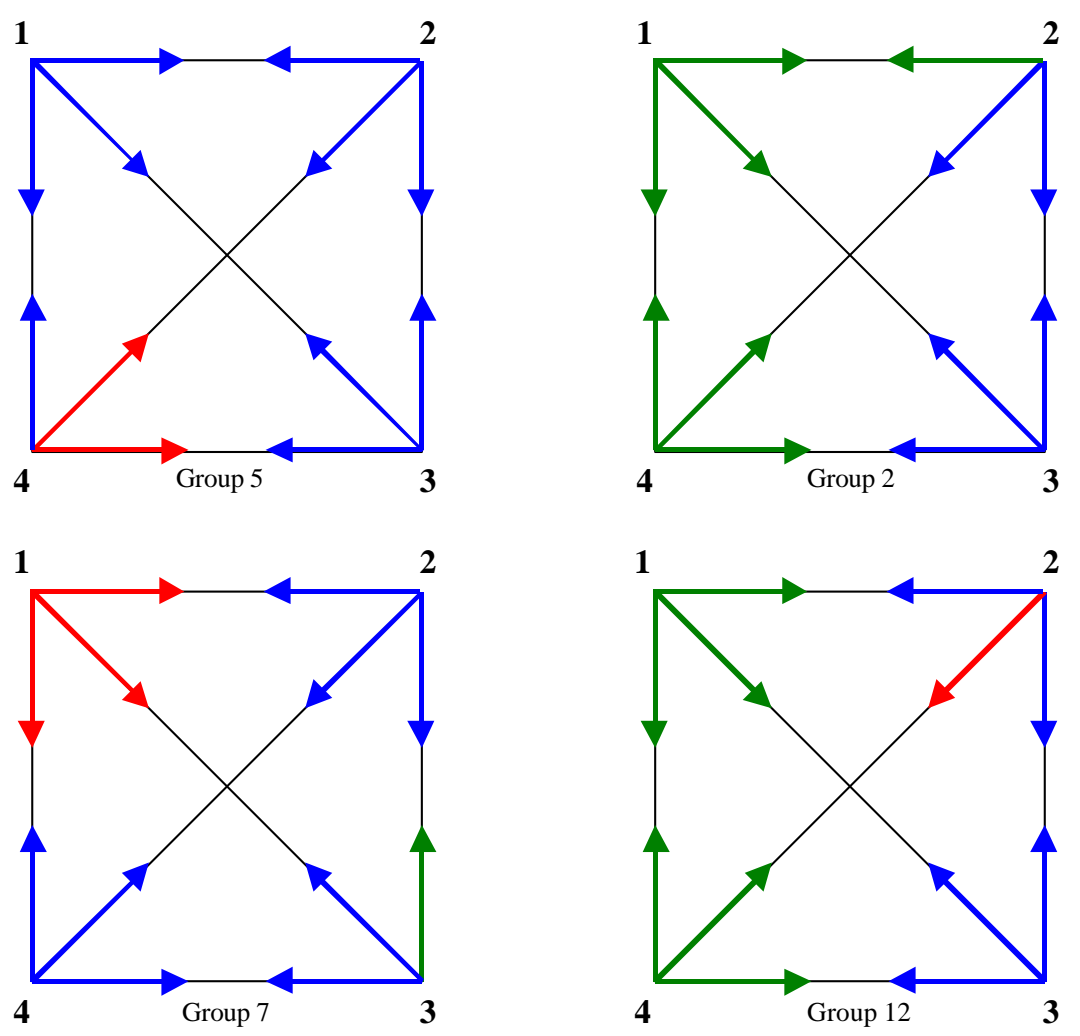

negative tie

neutral tie

positive tie

Figure 3. Social Networks in the two worst groups ( 5 and 7) and the two best groups (2 and 12). 


\section{Conclusion}

This experimental study of informal group formation, through the development of social ties structures, shows two main results. First, prolonged functional interaction in a public good game leads to the development of social ties, the valence of which depends on the success of the interaction in terms of contributions to the public good. ${ }^{7}$ Since a social tie refers to the difference between the weight that an individual attaches to the well-being of a specific other and the weight given to the well-being of a generalized (randomly selected) other, the success of the interaction is partly determined by the individual's social value orientation, which measures the latter weight. In this respect our results corroborate earlier findings indicating that subjects already start out with very different distributional preferences. However, these preferences appear to change due to affective responses to the beneficial or harmful behavior of those interacted with. In the experiment this happened with $54 \%$ of the subjects.

Second, subjects discriminate between group members on the basis of their relatiive contributions, that is, relative to the contributions of other group members. The resulting dynamics appears to generate a variety of social ties between group members. Most (66\%) of the ties turn out to be asymmetric, notwithstanding the shared interest in the public good, the equal endowments and the identical payoff structures. This study suggests that individual differences in social value orientation and (affective) reaction patterns that are not controlled for are responsible for this. Focusing on the best and worst performing groups in terms of contributions to the public good, we find that the nature of the social ties structures (networks) differs considerably between groups. Whereas most of the ties among members of the best performing groups are (mutually) positive, most of the ties in the worst performing groups are either negative or neutral. However, also in the successful groups networks are far from complete and asymmetry occurs.

Social dynamics turn out to be complicated. Even when individuals share objectives, and preferences and endowments are identical, very different outcomes are possible, depending on social value orientations and individual reaction patterns. Thus, even under favorable circumstances, pervasive positive social ties cannot be expected. Affective responses, based on sentiments and emotions, are not a panacea for the failures of rational selfishness, as is sometimes suggested (Hirshleifer 1987). This has important implications. For example, our findings produce new insights on why local communities or neighborhoods sometimes succeed in the private provision of public goods, whereas on other occasions they do not. These findings provide a rationale for (selective) government intervention which duely takes account of the dynamics of the social ties structure within the community. In this context, interesting issues for future research concern the impact of government policies with respect to housing, education (schools) and mobility, for instance. Similarly, in work situations, managers cannot take it for granted that social interaction will go well among equals, and that work performance will be high. Our findings

\footnotetext{
${ }^{7}$ This result corroborates the finding of van Dijk, Sonnemans and van Winden (1997) for a two-person instead of four-person public good game.
} 
show that subjects can set into motion a destructive social dynamic, by underperforming. In both settings of work and community, the results suggest the importance of leadership in controlling and channeling emotions and sentiments to build effective teams and communities. This supports a rather different perspective on management and hierarchy than the one provided by standard agency theory. While providing monetary incentives and monitoring behavior remain important, the role of managers appears to go much further than that.

\section{References}

Akerlof, G. A., 1983, Loyalty filters, American Economic Review 73, 54-63.

Aldrich, H., 1995, Is Japan different? The personal networks of Japanese business owners compared to those in four other industrialized nations, KSU Economic and Business Review 22, 1-28

Baumeister, R. F., and M. R. Leary, 1995, The need to belong: desire for interpersonal attachments as a fundamental human motivation, Psychological Bulletin 117, 497-529.

Becker, G. S., 1981, A Treatise on the Family, Harvard University Press, Cambridge.

Bernheim, D. B., 1994, A theory of conformity, Journal of Political Economy, 102, 841-877.

Boorman, S. A., 1975, A combinatorial optimization model for transmission of job information through contact networks, Bell Journal of Economics 6, 216-249.

Coleman, J. S., 1984, Introducing social structure into economic analysis, American Economic Review, Papers and Proceedings 74, 84-88.

Coleman, J. S., 1990, Foundations of Social Theory, Harvard University Press, Cambridge.

Dasgupta, P., 1999, Economic progress and the idea of social capital, in: P. Dasgupta and I. Serageldin (eds.), Social Capital; A Multifaceted Perspective, The World Bank, Washington, 325-424.

van Dijk, F., and F. van Winden, 1997, Dynamics of social ties and public good provision, Journal of Public Economics 64, 323-341.

van Dijk, F., J. Sonnemans and F. van Winden, 1997, Social ties in a public good experiment, mimeo, University of Amsterdam.

Fararo, T. J., 1989, The Meaning of General Theoretical Sociology, Cambridge University Press, Cambridge.

Feld, S. L., 1981, The focused organization of social ties, American Journal of Sociology 86, 10151035.

Forsyth, D. R., 1990, Group Dynamics, second edition, Brooks/Cole, Pacific Grove.

Frey, B. S., 1997, Not Just for the Money, Edward Elgar, Brookfield.

Granovetter, M., 1985, Economic action and social structure: the problem of embeddedness, American Journal of Sociology 91, 481-510.

Granovetter, M., 1992, The sociological and economic approaches to labor market analysis: a social structural view, in: M. Granovetter and R. Swedberg (eds.), The Sociology of Economic Life, Westview Press, Boulder, 223-265.

Hirshleifer, J., 1987, On the emotions as guarantors of threats and promises, in: J. Dupré (ed.), Latest on the Best; Essays on Evolution and Optimality, MIT press, Cambridge, 307-326. 
Holländer, H., 1990, A social exchange approach to voluntary cooperation, American Economic Review 80, 1157-1167.

Homans, G. C., 1950, The Human Group, Harcourt, Brace and World, New York.

Homans, G. C., 1961, Social Behaviour; Its Elementary Forms, Routledge \& Kegan Paul, London.

Kreps, D. M., 1997, Intrinsic motivation and extrinsic incentives, American Economic Review, Papers and Proceedings 87, 359-364.

Ledyard, J. O., 1995, Public goods: a survey of experimental research, in: J. H. Kagel and A. E. Roth (eds.)., The Handbook of Experimental Economics, Princeton University Press, Princeton, 111194.

Levine, J. M., and R. L. Moreland, 1998, Small groups, in: D. T. Gilbert, S. T. Fiske and G. Lindzey (eds.), The Handbook of Social Psychology, fourth edition, vol. 2, McGraw-Hill, Boston, 415469.

Liebrand, W. B. G., 1984, The effect of social motives, communication and group sizes on behavior in an n-person multi stage mixed motive game, European Journal of Social Psychology 14, 239264.

Keser, C., and F. van Winden, 1999, Conditional cooperation and voluntary contributions to public goods, forthcoming in: Scandinavian Journal of Economics.

La Porta, R., F. Lopez-de-Silanes, A. Shleifer and R. Vishny, 1998, Law and finance, Journal of Political Economy 106, 1113-1155.

Marshall, A., 1961 [1890], Principles of Economics, MacMillan, London.

Offerman, T., J. Sonnemans and A. Schram, 1996, Value orientation, expectations and voluntary contributions in public goods, Economic Journal 106, 817-845.

Okun, A., 1981, Prices and Quantities: A Macroeconomic Analysis, Brookings Institution, Washington.

Rotemberg, J. J., 1984, Human relations in the workplace, Journal of Political Economy 102, 684-717.

Rusbult, C. E., and P. A. M. van Lange, 1996, Interdependence processes, in: E. T. Higgins and A. W. Kruglanski (eds.), Social Psychology: Handbook of Basic Principles, Guilford, New York, 564596.

Scott, W. R., 1981, Organizations, Prentice Hall, Englewood Cliffs.

Smith, A., 1984 [1759], The Theory of Moral Sentiments, Liberty Fund, Indianapolis.

Sonnemans, J., A. Schram and T. Offerman, 1998, Public good provision and public bad prevention: the effect of framing, Journal of Economic Behavior and Organization 34, 143-161.

Sonnemans, J., A. Schram and T. Offerman, 1999, Strategic behavior in public good games: when partners drift apart. Economics Letters 62, 35-41.

Turner, J. H., 1999, The formation of social capital, in: P. Dasgupta and I. Serageldin (eds.), Social Capital; A Multifaceted Perspective, The World Bank, Washington, 94-146.

Uzzi, B., 1996, The sources and consequences of embeddedness for the economic performance of organizations: the network effect, American Sociological Review 61, 674-698. 


\section{Appendix}

\section{SUMMARY OF THE INSTRUCTIONS}

The instructions of all three parts of the experiment are fully computerized. To safe space we provide only a summary of the three parts of the experiment.

\section{Part 1}

You are asked to make a single choice. The choice concerns the allocation of points to yourself and to a randomly chosen other subject ('the other'); 200 points equal 1 guilder. Your options are depicted on the next screen. Each point on the circle gives a combination of points you receive or loose and points the other receives or looses. Choose now a point on the circle with the mouse. When you click, the corresponding points for you and the other are revealed. By clicking on other points of the circle, other combinations you may choose become visible. You are now asked to answer two questions to check your understanding <...not reproduced here...>.

The other subject with whom you will be linked has to take a similar decision. Your reward is determined by your own choice and the choice of the other. During the experiment you will not receive any information about the choice made by the other. When you get paid out, once the whole experiment has finished, you will informed about the choice of the other.

To check your understanding of the procedure, we will ask you two further questions < <...not reproduced here...> The exercises are finished. You are now asked to choose a combination of points for yourself and of points for the other.

\section{Part 2}

\section{Introduction}

Part 2 consists of 32 periods. In each period you are asked to take a decision. Each decision concerns the distribution of 10 markers over two activities: activity $\mathrm{X}$ and activity $\mathrm{Y}$.

Activity X leads to a payoff for yourself only. Activity $\mathrm{Y}$ leads to a payoff for yourself and also for three other subjects. Each of the three other subjects has to take similar decisions: activity X leads to a payoff for her/himself only. Activity Y leads to a payoff not only for this participant, but also for you and the other two participants. After each period you are informed about the decisions of the three others. You will be paid after the end of the experiment.

To avoid any misunderstandings: the subject you were paired with in the first part of the experiment is not among the three subject you will now be linked with. Part 1 and Part 2 are completely independent of each other.

The three subjects with whom you will interact are called A, B and C. During all 32 periods A, B and C remain the same subjects.

\section{Payoff information}

On the next screen the upper-left corner shows you a summary of how your payoffs from the activities $\mathrm{X}$ and $\mathrm{Y}$ are determined. This summary remains visible during the experiment.

Your payoff from activity $\mathrm{X}$ depends on the number of markers you yourself spend on this activity. The column 'value' shows the payoff of each marker that you spend on activity X. As you see, each extra marker pays you less. The column 'sum' shows you the total payoff for each number of markers that you spend on X.

Your payoff from activity Y depends on the total number of markers that you and the other three participants spend on this activity. Each marker pays you and each of the three others 7 points.

In each period fixed costs will be subtracted from your payoffs, namely 60 points. Thus, your total earnings per period will be: the payoff from activity X PLUS the payoff from activity Y MINUS the fixed costs.

On your handout 'Overview of earnings and costs per period' you find the same information as you can see now in the upper-left corner of your screen. On the other handout 'Table of total earnings' the earnings for all possible combinations of markers allocated to activity $\mathrm{X}$ and $\mathrm{Y}$ are listed.

\section{Making a decision}

We will now practice how decisions are taken. On the next screen you are instructed how to type in your decision. First you type in how many of your 10 markers you want to spend on activity X. Then, the number of markers for activity Y. You will subsequently be asked to confirm your decision. After confirmation you cannot change your decision anymore.

\section{Registration table}

At the bottom of the screen, you see now the REGISTRATION TABLE. In this table your decisions, the decisions of the three others and the earnings are recorded. This table will always be visible. 
Questions and excercises

To check your understanding of the experiment you are now requested to answer some questions and to do a number of exercises.

You are ready now with the exercises. Period 1 will start, once all participants are ready.

Periods $1-25$

\section{After period 25}

We interrupt part 2 of the experiment and start with the third part. After part 3 has finished, we will continue with part 2 .

\section{Part 3}

You will be asked the same question as in part 1, namely to choose between several combinations of points for yourself and for another. However, this other is not randomly chosen as was the case in part 1, but is one of the participants with whom you are linked in part 2. You will be asked to take three decisions. In these three decisions the other is, subsequently, participant $\mathrm{A}, \mathrm{B}$ and $\mathrm{C}$ of part 2 of the experiment. The others will take similar decisions. Your earnings are again determined by your own decisions and the decisions by the other three participants. Also during this part of the experiment you will not receive information about the decisions of the others. Only after the experiment you will be informed about your earnings.

To refresh your memory, we ask you to do an exercise. You are ready with the exercise. You are now asked to take the three decisions. $<\ldots . . . .>$

Part 3 of the experiment has finished. As soon as everybody is ready, we will continue with part 2.

\section{Continuation of part 2: periods 26-32.}


OVERVIEW OF EARNINGS AND COSTS PER PERIOD

EARNINGS MARKERS IN X

\begin{tabular}{|c|c|c|}
\hline MARKER & VALUE & sun \\
\hline & OF MARKER & \\
\hline 1 & 20 & 20 \\
\hline 2 & 18 & 38 \\
\hline 3 & 16 & 5 \\
\hline 4 & 14 & 6 \\
\hline 5 & 12 & 8 \\
\hline 6 & 10 & 9 \\
\hline 7 & 8 & $9 \varepsilon$ \\
\hline 8 & 6 & \\
\hline 9 & 4 & 10 \\
\hline 10 & 2 & \\
\hline
\end{tabular}

EARNINGS MARKERS IN Y

\begin{tabular}{|c|c|c|}
\hline MARKER & VALUE & SUM \\
\hline & OFMARKER & \\
\hline 1 & 7 & 7 \\
\hline 2 & 7 & 14 \\
\hline 3 & 7 & 21 \\
\hline 4 & 7 & 28 \\
\hline 5 & 7 & 35 \\
\hline 6 & 7 & 42 \\
\hline 7 & 7 & 49 \\
\hline 8 & 7 & 56 \\
\hline 9 & 7 & 63 \\
\hline 10 & 7 & 70 \\
\hline 11 & 7 & 77 \\
\hline 12 & 7 & 84 \\
\hline 13 & 7 & 91 \\
\hline 14 & 7 & 98 \\
\hline 15 & 7 & 105 \\
\hline 16 & 7 & 112 \\
\hline 17 & 7 & 119 \\
\hline 18 & 7 & 126 \\
\hline 19 & 7 & 133 \\
\hline 20 & 7 & 140 \\
\hline 21 & 7 & 147 \\
\hline 22 & 7 & 154 \\
\hline 23 & 7 & 161 \\
\hline 24 & 7 & 168 \\
\hline 25 & 7 & 175 \\
\hline 26 & 7 & 182 \\
\hline 27 & 7 & 189 \\
\hline 28 & 7 & 196 \\
\hline 29 & 7 & 203 \\
\hline 30 & 7 & 210 \\
\hline 31 & 7 & 217 \\
\hline 32 & 7 & 224 \\
\hline 33 & 7 & 231 \\
\hline 34 & 7 & 238 \\
\hline 35 & 7 & 245 \\
\hline 36 & 7 & 252 \\
\hline 37 & 7 & 259 \\
\hline 38 & 7 & 266 \\
\hline 39 & 7 & 273 \\
\hline 40 & 7 & 280 \\
\hline
\end{tabular}

COSTS PER PERIOD: 60 
Table of total earnings

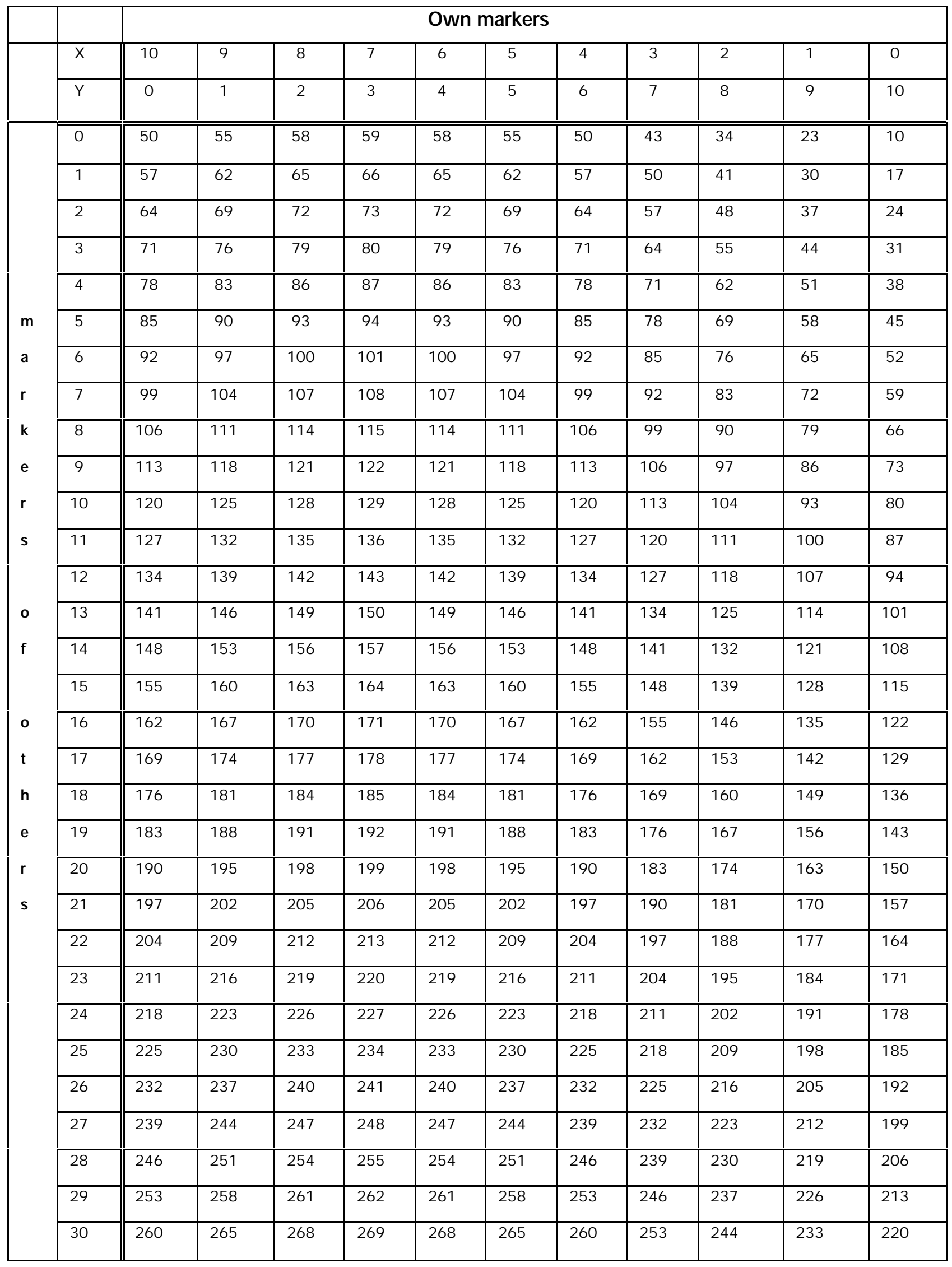

